\title{
LEONARDO PADURA Y LA POÉTICA DE UNA NUEVA ESCRITURA POLÍTICA. PRESENTACIÓN
}

POR

\author{
Ana María Amar Sánchez y Claudia Hammerschmidt
}

Leonardo Padura es un escritor que ha estado en los últimos años en el centro del interés tanto de la Academia como del público en general. Cada novela publicada ha provocado comentarios, estudios y polémicas. Sin duda esto se debe en parte a su condición de autor cubano que vive en la isla y a que sus ficciones y ensayos no se privan de tener un elevado contenido político y crítico. La situación cubana, en particular a partir de los cambios producidos en años recientes, es objeto de mucha atención, más allá de que las posturas sean "a favor" o "en contra". Padura se halla entonces en algo que se podría llamar el "ojo del huracán": muy reconocido y leído en el exterior, su producción es analizada, casi inevitablemente, desde perspectivas políticas, a veces como único centro de interés, incluso dejando de lado su condición literaria.

Esta articulación en torno a lo político tiene varias inflexiones. Como se sabe, Padura se vuelve un escritor reconocido durante la década de los ' 90 por su Tetralogía de las cuatro estaciones compuesta por sus primeras y muy exitosas novelas detectivescas (Pasado perfecto [1991], Vientos de cuaresma [1994], Máscaras [1997] y Paisaje de otoño [1998]). Esto ha dado lugar a otra vertiente del interés crítico, centrado en su uso del policial, su conexión con algunos autores latinoamericanos y europeos cultores del género, y en las alternativas que genera para la discusión en torno a la verdad, la ley y la politización de las fórmulas canónicas. Sin duda, los estudios en esta línea son muy numerosos en tanto permiten enfocarse en el aspecto literario y, a la vez, en la crítica política que contiene la trama de las novelas y cuentos. El policial abre una serie de posibilidades que incluyen el análisis de cuestiones como la representación del mundo urbano -específicamente el de La Habana-, la homofobia, la presencia de la imagen y de los ambientes de la bohemia artística, tópicos que funcionan como espacios literarios y políticos simultáneos. Asimismo, relatos como La novela de mi vida [2002], El hombre que amaba a los perros [2009] y Herejes [2013] introducen otra alternativa para el estudio de su obra: la historia cubana -desde el siglo XIX al presente-, la europea-la del Partido Comunista español y ruso, los conflictos religiosos, la Guerra Civil española, la segunda Guerra Mundial-y su incidencia en la isla. Este 
tejido de relaciones permite nuevas inflexiones en el tratamiento de lo político y también nuevas alternativas para la crítica que puede leer esta producción a la luz de diversas perspectivas.

La presente antología tiene su origen en un panel organizado para el congreso del Instituto Internacional de Literatura Iberoamericana realizado en México en junio de 2014. Ese encuentro fue el punto de partida para reunir un conjunto más amplio de críticos que representan una diversidad de puntos de vista, tanto en el tratamiento de los aspectos literarios como sociales y políticos. De esta manera, los ensayos que aquí se incluyen enfocan la narrativa de Padura atendiendo a diferentes ángulos: desde un análisis de su intento de desarrollar una poética de la desilusión política hasta el diálogo que establece con la cultura cubana, su literatura y el arte latinoamericanos y europeos. En todos ellos, estética y política se imbrican de modos complejos, lo cual permite examinar la nueva propuesta de una escritura que se posiciona políticamente y que a la vez se presenta como reflexión meta-estética sobre las (im)posibilidades de la representación. El foco de interés está concentrado en cómo Padura establece su compromiso literario por medio de estrategias que oscilan entre un neorrealismo y un nuevo "arte por el arte" dedicado al experimento estético y al juego intertextual. Los trabajos estudian la funcionalización que adquieren sus técnicas a la hora de construir una nueva escritura política destinada a la representación de la historia política de Cuba y a la reescritura de sus voces calladas. Todos "navegan" entre esos polos -estético y político- que definen la narrativa de Padura, ya sea inclinándose hacia uno u otro o tratando de mantener el equilibrio y la fusión entre ellos. La antología, más allá de los puntos de contacto entre los artículos que hacen difícil establecer diferencias tajantes, ha sido organizada en dos grupos según los enfoques dominantes en ellos: la preocupación por el análisis de aspectos estéticos por una parte y la atención mayor a cuestiones históricas y políticas por otra. De este modo, una primera sección -"La política en tensión: estética y ética"-reúne ensayos que dan cuenta, especialmente, de diversos mecanismos literarios en los textos de Padura; en la segunda -"La literatura en tensión: política e historia"-se encuentran estudios que se interesan por aspectos históricos y sociales más generales y abarcan, de algún modo, el conjunto de tópicos tratados.

Los ensayos de Dávila y van Tongeren leen las novelas desde una perspectiva claramente literaria y articulan su análisis teniendo en cuenta cuestiones teóricas que iluminan nuevos aspectos de la narrativa de Padura. Lourdes Dávila, en "Incitación del gesto. Teatro e historia en Máscaras, de Leonardo Padura Fuentes", desarrolla su argumentación a partir de la noción de gesto siguiendo la conocida definición de Giorgio Agamben. El ensayo explora esta noción en Máscaras, policial en el que el centro de la búsqueda es Alexis Arayán Rodríguez, personaje cuya última acción antes de ser asesinado es vestirse de travesti con el vestuario preparado para la representación de la obra de Electra Garrigó de Virgilio Piñera. Mario Conde, obsesionado con entender

$1111 \frac{\text { Revista Iberoamericana, Vol. LXXXV, Núm. 269, Octubre-Diciembre 2019, } 1145-1151}{\text { ISSN 2154-4794 (Electrónico) }}$ 
la apariencia y revelación sexual del travesti, se interesa por los gestos, en los que se incluyen los movimientos con los cuales se conforma el devenir y la repetición histórica. Dávila elude los enfoques más frecuentes en el tratamiento de este tema y lee Máscaras como una novela donde erotismo, historia y política delatan la pérdida de objetivos a la vez que analiza el gesto y el movimiento como la constante constructiva en los libros de la serie policial de Leonardo Padura; máscara, actuación teatral y travestismo coinciden y se vuelcan hacia el espacio de la política para metaforizar el engaño y la simulación y convertirlos en una alegoría del periodo pos-revolucionario. A su vez, Carlos van Tongeren sostiene en "La distribución de los cinismos en la narrativa de Leonardo Padura" que su producción novelística traza un mapa del desencanto en la sociedad cubana del Periodo Especial, situando esta coyuntura a la luz de otros momentos de la historia. El análisis parte de un concepto que impregna la mayoría de las ficciones y que se relaciona íntimamente con el desencanto -el cinismo-; van Tongeren sigue a Peter Sloterdijk en su definición del cinismo como una "fisura" en la conciencia que le permite al sujeto moderno proclamar una ideología sin creer en ella, o denunciar y al mismo tiempo perpetuar la decadencia y la corrupción. En las novelas de Padura, los personajes se acusan mutuamente de una actitud cínica a la vez que reflexionan sobre el anclaje del cinismo en una cultura general de desencanto - $\mathrm{O}$ "cansancio histórico"frente a las grandes utopías. Este vaivén entre la justificación y la acusación del sujeto cínico no sólo se pone de relieve en las novelas protagonizadas por Mario Conde, sino también en el capítulo final de El hombre que amaba a los perros, en el que un personaje que tramó el asesinato de Trotski confiesa que su cinismo fue un vehículo para soportar la cultura de miedo generada por el aparato estalinista. En la línea de la reflexión de Sloterdijk, los apuntes sobre el cinismo que se encuentran a lo largo de las novelas de Padura hacen gala de la necesidad de seguir separando entre víctimas y culpables, a la vez que apuntan al carácter difuso de dicha frontera.

Amar Sánchez y Hammerschmidt se interesan en particular por la tensión entre el campo de lo estético y de lo político en la ficción de Padura. El ensayo de Ana María Amar Sánchez, "La imagen como pretexto. la narrativa de Padura entre la política y la estética", analiza el entramado entre estética y política en parte de la producción de Leonardo Padura: el cuento "La puerta de Alcalá", las novelas Paisaje de otoño y Herejes. Se trata de ficciones que establecen un fuerte nexo entre una diversidad de formas estéticas y las referencias histórico-políticas: los efectos de la Revolución cubana, el desencanto, las semejanzas con otros proyectos revolucionarios fracasados o traicionados. El ensayo se enfoca en una de esas formas estéticas que resulta ser una estrategia central en varios relatos: el uso de la pintura (ya sean cuadros existentes o imaginarios) funciona como elemento clave en la trama, desencadenante, desvío, excusa y también nudo esencial para la reflexión política del texto. Asimismo, la puesta en relación de las obras de Padura con El tríptico de la infamia de Pablo Montoya -en el que también la pintura cumple un rol esencial- permite ver tanto significativas

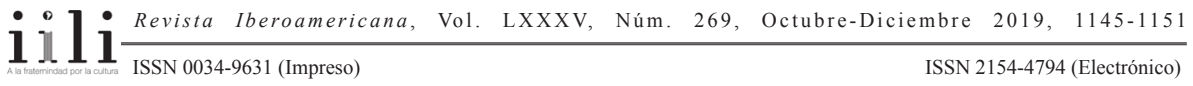


diferencias entre los dos escritores, como así también la función política de lo visual que ambos proponen. Claudia Hammerschmidt, en "Estéticas en lucha. La sublimidad de la pérdida en La novela de mi vida o el realismo estético de Leonardo Padura", estudia el modo en que el autor relaciona el recurso a la sublimidad de la naturaleza americana, la invención de la cubanía y la constitución del autor moderno con la experiencia del destierro sufrido por José María Heredia a partir de los años veinte del siglo XIX. Según Padura, autor que nunca dejó de vivir en la isla, la nostalgia del exiliado se traduce en una poética sublime que se constituye en fundadora de la poesía cubana. Sin embargo, al confrontar este modelo autorial con la vida ficticia de Fernando Terry, frustrado biógrafo de Heredia y exiliado del régimen castrista desde 1980, lo que podría parecer una apoteosis del exilio se convierte en un profundo análisis de la política de la isla desde la perspectiva de la pérdida. En la novela, esta pérdida se pone en escena en toda su ambivalencia: como pérdida del lugar o destierro que se asemeja a la experiencia de lo inefable, como pérdida de ideales o inacción que nace de la desilusión política, y como pérdida de la palabra o silencio establecido por la (auto)censura. De esta manera, la búsqueda de Terry por la supuesta autobiografía de Heredia y la narración tripartita entre diversas voces y épocas convierten el texto en un palimpsesto de la historia política de la isla y al mismo tiempo en la ilustración de distintas (des)figuraciones del autor y de la lucha por la representación literaria de Cuba.

Por su parte, María Pizarro Prada se concentra en la problemática función de la escritura y su capacidad representativa en Padura. En "'Pero escribí y el crimen fue menor'. Mario Conde y la escritura" explora los diferentes roles que la escritura toma en su obra, especialmente en las novelas protagonizadas por Mario Conde, a partir de una cita del mismo Padura: "Lo que pienso, lo que siento, lo que sufro lo canalizo a través de Conde. Podría escribirlo en artículos periodísticos, pero no hay espacio y el que hay está ocupado por la ortodoxia, por eso las novelas de policía son crónicas de la realidad cubana contemporánea". Al igual que la escritura desempeña un papel cuasi "exorcizador" para el autor, en una vuelta meta-ficcional, la escritura es también para Mario Conde su método de "limpieza de conciencia". La castración de la literatura metaforizada en el cuento que le censuraron en el PRE y en la novela Máscaras es sólo una de las denuncias que la escritura encarna, pues el propio acto de escribir y su continuo cuestionamiento son en Padura un refuerzo temático-estilístico de la búsqueda de una realidad que no atina a comprender. Si la realidad no es fiel a la imagen que se tiene de ella, y los casos son irresolubles en su totalidad por su vinculación con corrupciones en esferas inalcanzables, la pregunta en que se centra el artículo apunta a la fiabilidad del lenguaje y su posible capacidad para enunciar realidades y verdades.

La figura del protagonista por antonomasia de muchas novelas de Padura, Mario Conde, funciona también como eje que permite tomar diversas vías de reflexión en el trabajo de Jonathan Dettman, "Libertad condicional: subjetividad política e histórica en Herejes". Dettman sostiene que Mario Conde focaliza una conciencia histórica que,

$111 \frac{\text { Revista Iberoamericana, Vol. LXXXV, Núm. 269, Octubre-Diciembre 2019, } 1145-1151}{\text { ISSN 2154-4794 (Electrónico) }}$ 
por un lado, representa a una generación de cubanos y, por otro, intenta universalizar aspectos de su experiencia. Por ello se percibe en Herejes una suerte de nivelación histórica, en la que todos los casos de opresión se convierten en una cuestión de inconformidad social. Esta experiencia compartida permite la exploración literaria de paralelos entre épocas tan diversas como el Período Especial, la década de los 60 en Cuba, la Guerra Civil Española y la Ámsterdam del siglo XVII. Se funden así varias épocas históricas en una subjetividad narrativa que es, a su vez, plenamente histórica. Este sujeto histórico-literario es caracterizado tanto por su capacidad casi ilimitada para la autorreflexión como por su incapacidad de intervenir en procesos sociales que trasciendan el ámbito personal; de este modo, los actos individuales de herejía o rebeldía adquieren un significado enorme en Herejes, obra en la que lo único que parece importar es la libertad de elección. Dettman afirma que, aunque Herejes es una obra que se esfuerza por universalizar la experiencia de los inconformes, el sujeto narrativo sigue anclado en la Cuba pos-soviética, como es el caso en todas las novelas de Padura escritas desde los '90.

El peso de la historia en las ficciones de Padura articula los trabajos de Rojas, Rubio y Duprey. El ensayo de Rafael Rojas, "Trotski y Cuba. Política, ficción e historia en la era pos-soviética", inscribe El hombre que amaba a los perros en una tradición de la narrativa latinoamericana que ha experimentado una rearticulación de la novela histórica y una ficción vinculada con el periodismo y con el relato testimonial. En esta tradición, Padura se presenta como una de las voces más significativas entre los autores cubanos de la isla y la diáspora. Rojas lee esta novela de Padura como un texto, a medio camino entre el relato real y la historia ficción, que dota de nuevas funciones simbólicas e ideológicas a la novela cubana a principios del siglo XXI. Para el autor, gran parte del impacto que ha producido en el público se vincula con una historia silenciada -la de Trotski y Mercader- y no reconocida en la esfera pública que se representa por medio del tejido de tres historias. La novela resulta así una confrontación con aquel silencio del poder por medio de una sofisticada ficcionalización de la historia que está caracterizando la poética literaria del autor. También José Martínez Rubio lee Herejes, en "La Historia entre la libertad y la derrota. La generación posrevolucionaria en Herejes de Leonardo Padura", como una red que entrecruza la Historia (con mayúscula) y la ficción en tanto la novela reúne tres historias hilvanadas por un misterioso cuadro de Rembrandt y por su ya clásico detective Mario Conde. Estos hilos conductores permiten recorrer La Habana de los años 30 y 40, el Ámsterdam del siglo XVII y, de nuevo, la isla cubana en pleno siglo XXI, tras los fracasos de la historia y la caída de las utopías. El artículo estudia estos tres espacios y tiempos, configurados a la luz de dos conceptos clave, la libertad y la derrota; lo que llama el carácter "turbio" del género policial es lo que permite elaborar una crítica sobre La Habana, o al menos contraponer una ciudad distinta al relato oficial de la Revolución. En opinión de Martínez Rubio, el retrato social de La Habana que realiza Leonardo Padura parte de la especificidad del género

$111 \frac{\text { Revista Iberoamericana, Vol. LXXXV, Núm. 269, Octubre-Diciembre 2019, }}{1145-1151}$ 
negro, nacido para sacar a la luz la parte oscura del entramado social, pero no desde una disidencia ni explícita ni implícita. Se plantea así una variedad tal de voces, de hablas y de discursos que alimentan una lectura en clave contemporánea acerca de La Habana del siglo XXI y su coyuntura política y social.

El ensayo de Jennifer Duprey, "Travesía de una utopía rota: ekphrasis e historia en El hombre que amaba a los perros de Leonardo Padura", analiza la representación literaria de la historia en esta novela y propone que esta representación se lleva a cabo a través del recurso literario de la ekphrasis. A partir del análisis literario la autora ofrece una propuesta para los estudios transatlánticos relacionada con el estatus de la novela histórica hoy en día: polemiza con las ideas de Fredric Jameson sobre la imposibilidad de la novela histórica actual y arguye que la del autor cubano es una novela histórica-transatlántica en su "sentido emergente", es decir "como materialización de una conciencia y un conocimiento históricos específicos de carácter abiertamente político". Se trata de una parte de la historia del siglo XX, marcada por la utopía comunista y su travesía transatlántica, que comprende la Revolución de Octubre en Rusia, la Guerra Civil española, la Cuba pos-revolucionaria y la del Periodo Especial. Padura lleva entonces al lector a vivir una experiencia desoladora al ver cómo la travesía de una utopía política rota movió la rueda de la historia del siglo XX. La perspectiva transatlántica también se encuentra en el trabajo de Angel Esteban, "Cuba, punto de (des)encuentro de la cultura occidental en la narrativa de Leonardo Padura", que de algún modo condensa preocupaciones expresadas en otros trabajos de esta antología. Esteban sostiene que Padura ha politizado y ha "abierto" cada vez más su narrativa: si en los noventa se ha centrado en la situación de la isla, en el nuevo siglo ha desarrollado una ficción que se libera del círculo cerrado de "lo cubano" y conecta la identidad nacional con fenómenos culturales, sociales, políticos e históricos más universales; es decir, en las novelas del presente siglo, Cuba sigue siendo el interés primordial, pero se encuentra permanentemente conectada con un mundo que está fuera de ella. El ensayo entonces analiza la función de los elementos externos en la configuración de la trama, teniendo en cuenta cómo se vinculan con la condición protagónica de Cuba en su producción. En ese encuentro de Cuba con el mundo occidental confluyen historia, política y literatura y aparecen elementos culturales, autores, intelectuales, pintores, como Hemingway, Trotski, el cuadro de Rembrandt, que no son cubanos, pero que de algún modo han dejado una huella más o menos visible y fundamental en la historia de la isla.

Los diez ensayos reunidos articulan una variedad de enfoques y puntos de vista; sin embargo, también es fácil observar vínculos entre ellos que se entretejen y que reiteran intereses comunes. Las tensiones entre el campo estético con el político e histórico son posiblemente las más notorias y se manifiestan de diversos modos; los artículos las encaran analizando el uso de estrategias narrativas, de la imagen, del género policial, de la historiografía, de múltiples manifestaciones culturales. En la

$1111 \frac{\text { Revista Iberoamericana, Vol. LXXXV, Núm. 269, Octubre-Diciembre 2019, }}{1145-1151}$ 
medida en que se trata de un autor en plena producción y del que esperamos nuevos textos, ensayos, novelas y cuentos, esta antología no puede ser sino parcial y ligada a la coyuntura en que surgió. Refleja entonces no sólo un momento en el desarrollo de la obra de Padura, sino también de la crítica interesada en ella. 
